\title{
How to Help Students Understand Lectures in Advanced Mathematics
}

\author{
Keith Weber, Timothy P. Fukawa-Connelly, Juan Pablo Mejía-Ramos, \\ and Kristen Lew
}

ABSTRACT. We first provide evidence that even lectures of high quality are not always well understood by students. Second, we discuss four ideas to help instructors and students in proof-based mathematics courses.

As part of a recent research study [1], [2], we videotaped and analyzed a real analysis lecture by the highly respected "Dr. A" and investigated how well six of his students understood it. We focused on his ten-minute proof of the following proposition:

If a sequence $x_{n}$ has the property that there exists a constant $r$ with $0<r<1$ such that $\left|x_{n}-x_{n-1}\right|<$ $r^{n}$ for any two consecutive terms in the sequence, then $x_{n}$ is convergent.

Dr. A identified for us five ideas that he was trying to convey:

1. Cauchy sequences can be understood as sequences that "bunch up."

2. If one does not have a limit candidate for a convergent sequence, one can show that it is convergent by showing that it is Cauchy.

3. The proof illustrates how to set up a proof to show a sequence is Cauchy.

Keith Weber is professor of mathematics education at Rutgers University. His email address is kei th. weber@gse . rutgers . edu.

Tim Fukawa-Connelly is assistant professor of mathematics education at Temple University. His email address is tim. fukawaconne11y@gmai1.com.

Juan Pablo Mejía-Ramos is associate professor of mathematics and mathematics education at Rutgers University. His email address is pab1o.mejía@gse. rutgers. edu.

Kristen Lew is postdoctoral associate of mathematics education at Arizona State University. Her email address is kristen. 1ew@ asu. edu.

For permission to reprint this article, please contact:

reprint-permission@ams.org.

DOI: http://dx.doi.org/10.1090/noti1435
4. The triangle inequality is useful in proving series in absolute value formulae are small.

5. The geometric formula should be part of one's mathematical toolbox to keep some desired quantities small.

Our team felt that Dr. A clearly conveyed points 2, 3, 4 , and 5. Two weeks later, after a mid-term examination, we showed three pairs of students from Dr. A's class the ten-minute proof video, along with a transcript of what Dr. A wrote on the blackboard, and asked them what Dr. A was trying to convey. After watching the video, one pair noted point 3 and another pair noted point 4 . None noted point 2, which Dr. A emphasized three times during his proof. Together with additional research findings, this study leads us to believe that the following four ideas explain this student behavior and can contribute to improved student learning.

Idea \#1: Students prioritize written work over oral comments, so we should write down the key points that we want students to learn.

When giving lectures in advanced mathematics, mathematics professors want to (i) help their students realize what constitutes an acceptable proof and (ii) teach their students how to construct a proof. A common way that professors manage this tension is to present the proof on the blackboard and supplement this presentation with commentary describing the thought processes used to produce it. The students' job in a mathematics lecture is also challenging. They are grappling with new abstract ideas. As the professor is speaking at a faster pace than the students can write, the students must prioritize certain ideas over others. It is natural for the students to focus on what is written on the blackboard; this is a traditional way by which teachers emphasize importance, and written comments have a permanence that oral comments lack.

Research shows that students forget things they don't write down and that instructors talk faster than students can write. Dr. A expressed four of his main points orally but did not write them down. Five of the six students did not record any of Dr. A's oral comments when reviewing the video. Their notes generally consisted of a 
verbatim copy of what Dr. A wrote on the blackboard. This suggests an intriguing hypothesis for why students might not learn in their advanced mathematics lectures: professors state their most important points orally, while students focus on what is being written down. Professors almost always record the formal parts of their lectures-definitions, theorems, and proofs - on the blackboard but often do not record mathematical methods or conceptual explanations on the blackboard. Since students' notes consist largely of what is on the blackboard, they do not record most of their professors' mathematical methods or conceptual explanations in their notes.

Our subsequent investigation of student understanding in eleven proof-based mathematics lectures across a variety of mathematical domains provides strong evidence that this hypothesis is accurate. We see no reason to fault mathematics professors or their students for their actions. What we suggest is that mathematicians' habits while lecturing and students' focus of attention do not mesh well together; students do not prioritize the mathematicians' oral commentary and consequently do not record some of the most important ideas in the lectures. We recommend that for each portion of a lecture (e.g., introducing a new concept, presenting a proof), the professor identify one to three main ideas that they wish to convey and explicitly write these ideas on the blackboard.

Idea \#2: Mathematicians and students have differing views on understanding advanced mathematics, so we

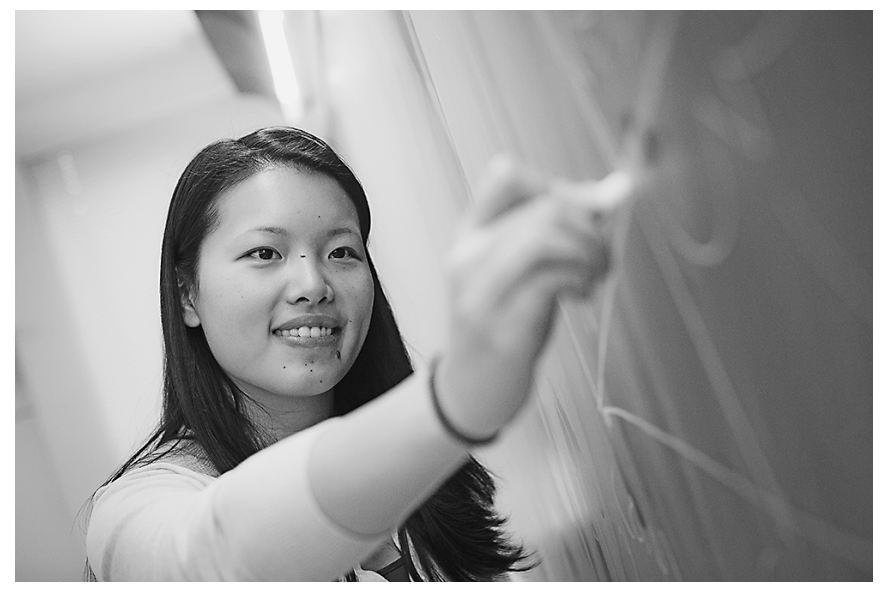

Kristen Lew presenting a proof and writing the main points of the proof on the blackboard.

should clearly communicate expectations about lectures from the outset.

In our research, we have found that mathematics professors and students usually share the same broad goals of mathematics lectures, namely that students will develop a better understanding of the course content by paying attention to the lectures. Where the two groups differ is on their perceptions of what it means to understand advanced mathematics [4]. For mathematicians, understanding a proof involves understanding why a proof is valid. However, mathematicians also feel that it is important to have a holistic understanding of a proof. A holistic understanding includes being able to summarize a proof, as well as recognizing the overarching methods employed in the proof and being able to apply these methods in new situations.

Students view things differently. They want to understand the proofs that they see in lecture and read in their textbook. However, to gain this understanding, many students focus exclusively on justifying how each new assertion follows from previous assertions. In high school geometry courses, proofs are often written in a twocolumn format where assertions are presented in the left column and an explicit justification for each assertion is presented in the right column. High school students subsequently view the purpose of proof not as providing explanation (or even verification) but as a test to demonstrate their ability to reason. Transition-to-proof courses often reinforce this by placing emphasis on how proofs can and should be structured. As students continue studying proof in their content-based proof-oriented mathematics courses, these beliefs become counterproductive, as an exclusive focus on the deductive logic in a proof can lead students to ignore the larger conceptual points that the professor is making.

Another discrepancy between mathematics professors' and students' expectations of lectures in mathematics is that these expectations are rarely the topic of explicit conversation. Lectures in advanced mathematics are a new experience for students; they can use ongoing guidance about the nature of this process and what their role in this process should be. We believe it is critical that professors clearly communicate expectations about lectures beginning early in the semester. We recommend that the professor be explicit about what they expect students to learn from the lecture and how they should engage in the material to learn it. Clearly such a conversation does not guarantee that students will engage in lectures productively, but it does provide students direction and the opportunity to understand the importance of doing so.

Idea \#3: When hearing a proof in a lecture, students often focus on calculation and logical detail, so we should shift what students attend to by assessing their understanding of other aspects of proofs.

In our interview with Dr. A, he highlighted the following excerpt in his lecture as a point where he was conveying an important mathematical point:

Dr. A: Now once again we ask the question. If we were to show this is small, we must represent it in terms of what we know is small. Well, what do you know is small? For $n$ large enough [gestures toward the statement of the theorem], the difference between two consecutive terms is 
small. [Turns and faces the blackboard] So what we must do is represent that as a sum of consecutive terms.

In this excerpt, Dr. A is giving an overview of the proof, emphasizing that what he must do is to show one quantity can be made sufficiently small when one knows that another quantity can be made arbitrarily small. By stating, "now once again we ask the question," he was conveying that this is a question that one should often ask oneself when writing such proofs. In our interview with Dr. A, he emphasized the importance of this clip:

Dr. A: Once you get into the area where you're doing approximations, you can't do equal, equal, equal. You have to have bounds, bounds, bounds. The objective is to show how bounds, using the triangle inequality, can be used to show that something is small using information that they're given is small. And this instance turns out that the information which is small is given in a form that allows us to use the geometric series as a bound.

Dr. A's intended point in the lecture excerpt above was obvious to us. When the three pairs of students were asked what Dr. A was trying to convey after rewatching the proof in its entirety, none of the students mentioned these ideas.

After showing the students the proof in its entirety, we showed students the specific short clip containing the transcript above and asked the students what Dr. A was trying to convey in this clip. Again, the students did not mention anything about keeping quantities small. Rather, all of the students focused on the algebraic manipulations and the logical details in the proof. For instance, one pair of students mentioned "basically manipulating the information that we're given so that we can show that a sequence fits the definition." Another pair said, "Given on the problem to see like what we could, how we can manipulate the problem statement. Just how we can start the proof in general." Dr. A made his meta-comments prior to presenting a string of algebraic manipulations to provide meaning and context to the manipulations that he would perform. To students who view understanding as tantamount to justifying the calculations, Dr. A's comments would seem to be superfluous and unnecessary to understand the proof that was presented.

Advanced mathematics lecturers strive to engage students with high-level or intuitive ways to understand the course content, but students are typically assessed on their ability to produce formal mathematics, such as stating definitions, applying procedures, or writing proofs. These assessments send a message to students that the formal aspect of mathematics is what is important and the other aspects of mathematics are superfluous. This likely contributes to students' propensity to focus on calculations and derivations while not prioritizing high-level summaries of the proof. We recommend assessing students on high-level and informal aspects of mathematical proofs as well. Of course, this will motivate students to understand the material, but there are two other benefits as well. First, the types of questions that students are asked can give them a better sense of how the material should be understood. Second, students' responses to these questions will provide the instructor with a better sense of how the students are interpreting his or her lecture. We provide in [3] a template for how proof comprehension can be assessed. Discussing the meaning of specific proofs with students can help the students understand what the professor is trying to convey.

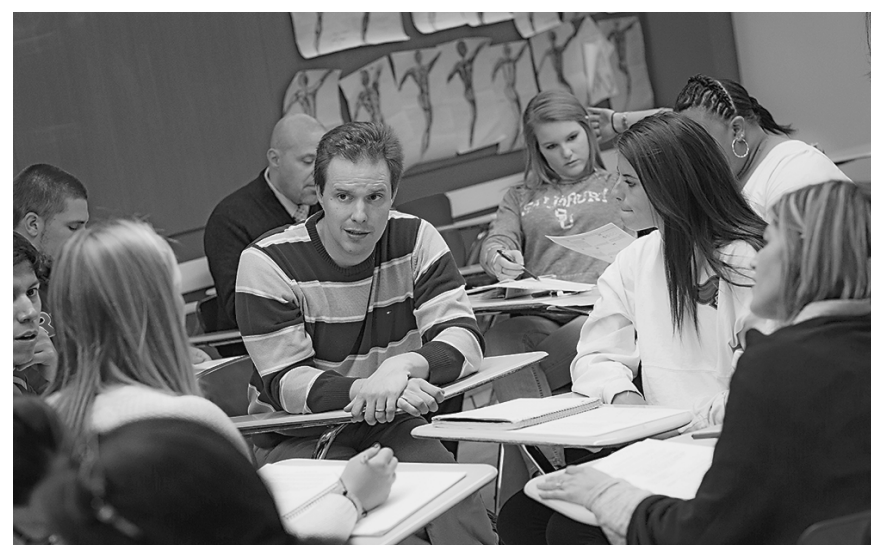

Keith Weber working with students to help them understand a proof.

Idea \#4: Seek data on how students understand your lectures.

Ordinarily, in university mathematics instruction professors do not receive direct or immediate feedback on how students are interpreting their lectures. Rather, they rely on indirect measures such as their students' performance on exams and their comments on student evaluations, where it is difficult to posit causal links between specific actions of the instructor and the responses of students. We believe that it is important for the professor to seek more direct feedback. One method that is commonly used in K-12 mathematics instruction is the notion of an "exit ticket," in which students are required to answer a short series of questions about their mathematics lesson before exiting the classroom. Asking students to say what they consider the three most important ideas of a lecture can provide valuable insight for the professor on how they interpreted a proof. This information can be used to shape subsequent lectures if students' interpretations of the lecture are different from what the professor intended.

\section{Acknowledgment}

This material is based upon the work supported by the National Science Foundation under grants DUE1245626 and DRL-0643734. Any opinions, findings, and conclusions or recommendations expressed in this material are those of the authors and do not necessarily reflect the views of the National Science Foundation.

\section{References}

[1] D. BRESSOUD, What they say/what we hear. Downloaded from: 1 aunchings.blogspot . com/2016/02/what-we-saywhatthey-hear.htm1. Last downloaded April 4, 2016.

[2] K. LEW, T. FuKAWA-CONNELly, J.P. Mejía-Ramos, and K. WEBER, Lectures in advanced mathematics: Why students might not understand what the professor is trying to convey, J. Res. Math. Ed., 47 (2016), 162-198. 
[3] J. P. Mejía-Ramos, E. Fuller, K. Weber, K. RhoAds, and A. SAMKOFF, An assessment model for proof comprehension in undergraduate mathematics, Educational Studies in Mathematics 79 (2012), 3-18.

[4] K. WEBER, Mathematics professors and mathematics majors' expectations of lectures in advanced mathematics," AMS Blog on Teaching and Learning Mathematics. Retreived from blogs . ams .org/matheducation/2015/02/10/ mathematics-professors-and-mathematics-majorsexpectations-of-1ectures-in-advanced-mathematics/

\section{Photo Credits}

Article photos are courtesy of Roy Groething.

INSTITUTE FOR ADVANCED STUDY

Summer Collaborators Program

The School of Mathematics at the Institute for Advanced Study invites applications from collaborators who would like to meet during the summer months to further their research project.

We can accommodate small groups (2-5 people) for periods of 2 to 4 weeks and provide a per diem, a modest amount of travel funds, office space, excellent library and computer facilities and local housing. Up to five groups will be selected.

Our campus is located on extensive grounds in Princeton, New Jersey, about an hour from New York City and Philadelphia. Available dates for 2017 are within the time periods of May 28 to July 31 .

We encourage applications from those with limited access to other research funding. However, if you or a member of your group has financial support, we would expect you to use those funds.

Application deadline is December 1 , 2016, and successful applicants will be notified in February 2017.

More information regarding the program can be found at https://www.math.ias.edu/summercollaborators

Please email any questions to summercollaborators@math.ias.edu 